\title{
Comparison of the sensitivity of culture, PCR and quantitative real-time PCR for the detection of Pseudomonas aeruginosa in sputum of cystic fibrosis patients
}

\author{
Pieter Deschaght ${ }^{1}$, Thierry De Baere ${ }^{1}$, Leen Van Simaey ${ }^{1}$, Sabine Van daele ${ }^{2}$, \\ Frans De Baets ${ }^{2}$, Daniel De Vos ${ }^{3}$, Jean-Paul Pirnay ${ }^{3}$ and \\ Mario Vaneechoutte*1
}

Address: ${ }^{1}$ Laboratory for Bacteriology Research (LBR), Ghent University Hospital, University of Ghent, Ghent, Belgium, ${ }^{2}$ Cystic Fibrosis Centre, Department Pediatric Pulmonology, Ghent University Hospital, University of Ghent, Ghent, Belgium and ${ }^{3}$ Laboratory for Molecular and Cellular Technology (LabMCT), Burn Wound Center, Queen Astrid Military Hospital, Brussels, Belgium

Email: Pieter Deschaght - deschaght.pieter@ugent.be; Thierry De Baere - Thierry.DeBaere@iph.fgov.be; Leen Van Simaey - Leen.Vansimaey@ugent.be; Sabine Van daele - Sabine.Vandaele@ugent.be; Frans De Baets - Frans.DeBaets@ugent.be; Daniel De Vos - Daniel.DeVos2@mil.be; Jean-Paul Pirnay - Jean-Paul.Pirnay@mil.be; Mario Vaneechoutte* - Mario.Vaneechoutte@ugent.be

* Corresponding author

Published: 29 November 2009

BMC Microbiology 2009, 9:244 doi:10.1 186/147/-2180-9-244

This article is available from: http://www.biomedcentral.com/l47|-2/80/9/244

(c) 2009 Deschaght et al; licensee BioMed Central Ltd.

This is an Open Access article distributed under the terms of the Creative Commons Attribution License (http://creativecommons.org/licenses/by/2.0), which permits unrestricted use, distribution, and reproduction in any medium, provided the original work is properly cited.
Received: 12 August 2009

Accepted: 29 November 2009

\begin{abstract}
Background: Pseudomonas aeruginosa is the major pathogen involved in the decline of lung function in cystic fibrosis (CF) patients. Early aggressive antibiotic therapy has been shown to be effective in preventing chronic colonization. Therefore, early detection is important and sensitive detection methods are warranted. In this study, we used a dilution series of $P$. aeruginosa positive sputa, diluted in a pool of $P$. aeruginosa negative sputa, all from CF patients - to mimick as closely as possible the sputa sent to routine laboratories - to compare the sensitivity of three culture techniques versus that of two conventional PCR formats and four real-time PCR formats, each targeting the $P$. aeruginosa oprL gene. In addition, we compared five DNA-extraction protocols.
\end{abstract}

Results: In our hands, all three culture methods and the bioMérieux easyMAG Nuclisens protocol Generic 2.0.I, preceded by proteinase K pretreatment and followed by any of the 3 real-time PCR formats with probes were most sensitive and able to detect $P$. aeruginosa up to $50 \mathrm{cfu} / \mathrm{ml}$, i.e. the theoretical minimum of one cell per PCR mixture, when taking into account the volumes used in this study of sample for DNA-extraction, of DNA-elution and of DNA-extract in the PCR mixture.

Conclusion: In this study, no difference in sensitivity could be found for the detection of $P$. aeruginosa from sputum between microbiological culture and optimized DNA-extraction and realtime PCR. The results also indicate the importance of the optimization of the DNA-extraction protocol and the PCR format.

\section{Background}

Patients with cystic fibrosis (CF), an autosomal recessively inherited disease caused by a mutation in the Cystic Fibro- sis Transmembrane Conductance Regulator (CFTR) gene, are particularly susceptible to pulmonary infections with Pseudomonas aeruginosa $[1,2]$. Colonization of the airways 
of CF patients with P. aeruginosa results in higher morbidity and mortality because of the faster decline of the lung function, especially from the chronic infection phase onwards [3-5]. Detection of colonization and infection by this pathogen as early as possible enables to postpone the chronic infective stage and eventually to achieve the eradication of $P$. aeruginosa through early treatment. Indeed, early aggressive antibiotic therapy is now generally accepted as an efficient means to postpone chronic colonization $[6,7]$.

In most routine laboratories detection of bacterial species in respiratory samples is achieved by culture. However, it has been shown that routine culture of sputa from CF patients yields limited microbiological information since it frequently fails to identify the pathogens, which were shown to be present by means of PCR [8]. Furthermore, the correct detection and identification of $P$. aeruginosa, although in general not a fastidious organism, is not as straightforward as frequently assumed $[9,10]$. To circumvent culture associated limitations, several molecular assays for the detection of Pseudomonas species have been described [8,11-19], Döring and colleagues [20] correctly remarked that, because of the influence of sample pretreatment, DNA-extraction protocol and the PCR format, there is a need for validation of the PCR techniques before these can be used in a routine laboratory. However, to our knowledge, no study systematically compared the sensitivity of different culture, DNA-extraction, PCR and realtime PCR methods for the detection of $P$. aeruginosa from CF sputum, by using a CF patient sputum based dilution series of $P$. aeruginosa.

Here, we compared the sensitivity of three culture media, five DNA-extraction protocols, two conventional PCR formats and four real-time PCR formats for the detection of $P$. aeruginosa, using a dilution series of $P$. aeruginosa positive sputa in a pool of $P$. aeruginosa negative sputa.

\section{Results}

In this study, we compared the sensitivity of different culture and PCR methods. To that purpose, we prepared a $P$. aeruginosa dilution series in CF sputum by diluting $P$. aeruginosa positive CF patient sputa in a pool of $P$. aeruginosa negative CF patient sputa. This was done instead of diluting cultured $P$. aeruginosa cells in saline or diluting $P$. aeruginosa positive sputum in saline or spiking sputa with $P$. aeruginosa cells, to mimick as closely as possible the sputum samples sent to routine laboratories.

\section{Comparison of culture methods}

No differences in detection limit could be observed between McConjey Agar (MCA) and Cetrimide Agar (CA), i.e. respectively an average of 2 and 3 colonies were counted at dilution eight. For Cetrimide Broth (CB) the detection range was also comparable with that of MCA and CA, i.e. P. aeruginos a could be detected up to dilution eight, but the number of colonies was too high to be countable (Table 1).

Based on these results, the number of culturable cells in the original sputum preparation was calculated to be 1.6 $\log 8 \mathrm{cfu} / \mathrm{ml}$.

\section{Comparison of DNA-extraction protocols}

For each sputum dilution, DNA was extracted by four protocols using the bioMérieux easyMAG Nuclisens semiautomated DNA-extractor and by the protocol for the manual High Pure PCR Template Preparation Kit (Roche). Results are listed in Table 1. In our hands, the BioMérieux easyMAG Nuclisens protocol Generic 2.0.1, combined with proteinase K pretreatment, was the DNA-extraction protocol that enabled the most sensitive detection of $P$. aeruginosa from sputum of CF patients, both with conventional and with qualitative PCR, giving amplification of the P. aeruginosa oprL target gene up to dilutions 6 and 8 , respectively. This DNA-extraction protocol was used further to compare a total of two different conventional PCR and four different (quantitative) real-time PCR formats.

\section{Comparison of different PCR and real-time PCR formats}

Conventional PCR, using the Veriti 96-Well Thermal Cycler (Applied Biosystems), combined with visualisation of the PCR products by agarose gel electrophoresis and ethidium bromide staining respectively by capillary electrophoresis and fluorescence measurement, was compared with three different real-time PCR formats using the LightCycler 1.5 (Roche) and with a commercially available P. aeruginosa specific real-time PCR (TaqMan assay) using the ABI7000 (Applied Biosystems). One real-time PCR format used SybrGreen fluorescence as the detection method, whereas the other three real-time PCR formats relied on the fluorescence generated by probes for detection.

Results are listed in Table 2. For the conventional PCR, combined with agarose gel electrophoresis, $P$. aeruginosa DNA could be detected up to dilution 6 , while with capillary electrophoresis amplified $P$. aeruginosa DNA could be detected up to dilution 7. P. aeruginosa DNA could be detected up to dilution 7 with real-time PCR using SybrGreen, and up to dilution 8 with real-time PCR with the Hybprobes, with the TaqMan probe and with the commercial Pseudomonas aeruginosa TaqMan probe detection kit on the ABI7000. In conclusion, the three probe based real-time PCR formats were the most sensitive molecular assays.

\section{Discussion}

Pseudomonas aeruginosa is the major pathogen in cystic fibrosis (CF) patients and is an indicator of poor prognosis in CF patients, especially from the onset of the chronic 
Table I: Comparison of the sensitivity of different DNA-extraction protocols as assessed by means of conventional PCR combined with agarose gel electrophoresis and by real-time PCR on LightCycler using TaqMan probe

\begin{tabular}{lllll}
\hline & Molecular detection & & \\
\hline Extraction & Protocol & Pretreatment & Last positive dilution \\
\hline & & & PCR $^{\mathrm{a}}$ & \\
\hline easyMAG & Generic 2.0.1 & Proteinase K & 6 & \\
\hline easyMAG & Generic 2.0.1 & None & 5 & 7 \\
\hline easyMAG & Specific B & Proteinase K & 5 & \\
\hline easyMAG & Specific B & None & 5 & 7 \\
\hline High Pure & Manual & Proteinase K & 5 & 7 \\
\hline
\end{tabular}

Detection by culture

\begin{tabular}{lc}
\hline McConkey Agar (MCA) & $8 c$ \\
\hline Cetrimide Agar (CA) & $8 c$ \\
\hline Cetrimide Broth with subculture on Blood Agar (CB) & 8 \\
\hline a Conventional PCR with primers PAOI S and PAOI A using the Veriti $96-$ Well Thermal Cycler. \\
b Real-time PCR with primers PAOI S and PAOI A and TaqMan probe oprL TM using the LightCycler I.5. \\
c The initial inoculum was calculated by averaging the number of cfu at dilution 8 on MC and CA, i.e. $2.5 \mathrm{cfu} / 50 \mu$ l, multiplying with 20 to obtain the \\
cfu/ml, i.e. 50 cfu/ml, multiplying with the dilution factor I/3 I 25000 to obtain the initial inoculum after dilution with Sputasol, i.e. 78 I $25000 \mathrm{cfu} / \mathrm{ml}$, \\
and finally multiplying with factor 2 to obtain the original number of cfu/ml of sputum, i.e. I56 $250000 \mathrm{cfu} / \mathrm{ml}$, or approx. I.6 log8 cfu/ml.
\end{tabular}

Table 2: Comparison of the sensitivity of the different PCR formats for sputum dilutions extracted with easyMAG Generic 2.0.I and proteinase $K$ pretreatment

\begin{tabular}{|c|c|c|c|c|c|}
\hline PCR format ${ }^{a}$ & Cyclerc & Primers & Probes & $\begin{array}{l}\text { Annealing temperature } \\
\left({ }^{\circ} \mathrm{C}\right)^{d}\end{array}$ & Last positive dilution \\
\hline I. PCR + AGEb & 1 & PAOI S/PAOI A & None & 55 & 6 \\
\hline 2. $P C R+F C E$ & 1 & PAOI S/PAOI A & None & 55 & 7 \\
\hline 3. real-time PCR + SybrGreen & 2 & PAOI S/PAOI A & None & 55 & 7 \\
\hline 4. real-time PCR + HybProbes & 2 & oprL F/oprL R & oprL-LC-ROX/oprL-LC-FAM & 57 & 8 \\
\hline $\begin{array}{l}\text { 5. real-time PCR + TaqMan } \\
\text { probe }^{b}\end{array}$ & 2 & PAOI S/PAOI A & oprL TM & 55 & 8 \\
\hline $\begin{array}{l}\text { 6. real-time PCR + TaqMan } \\
\text { probe }\end{array}$ & 3 & Not specified & Not specified & 60 & 8 \\
\hline
\end{tabular}

a AGE: Agarose gel electrophoresis + ethidium bromide staining; FCE: Fluorescent capillary electrophoresis on ABI3I0.

b PCR formats that were used to compare the sensitivity of the different DNA-extraction protocols (Table I).

c I: Veriti 96-Well Thermal Cycler, Applied BioSystems, Foster City, Ca.; 2: LightCycler I.5, Roche, Basel, Switzerland; 3: ABI Prism 7000 Sequence Detection System, Applied BioSystems.

d Annealing temperatures as specified by provider of primers and probes (PCR formats I-5) or by provider of commercial kit (PCR format 6). 
stage when colonies become mucoid and variant phenotypes emerge. Early detection is essential given the success of early aggressive eradication therapy [6,7]. Therefore, the most prevalent detection and identification methods, i.e. culture and (real-time) PCR, should be optimized to achieve the highest sensitivity.

West et al. [21] reported that specific $P$. aeruginosa antibodies were detectable between 6 and 12 months prior to the first positive culture for $P$. aeruginosa from respiratory samples. These findings suggest that culture may miss $P$. aeruginosa in the early stages of colonization. Also at later stages, culture can miss the emerging P. aeruginosa phenotypic variants such as the pyoverdine negative mutants, the slowly growing variants, the small colony variants and the auxotrophs, which do not grow on standard media $[9,10]$. Therefore, the development of improved culture methods and/or of molecular methods is warranted, not only for early detection but also for follow up of colonized patients. However, although several molecular assays for the detection of Pseudomonas species have been described (e.g., [11,13-19,22-26]), surprisingly few studies have compared selective and nonselective culture methods with the different molecular methods that have been described for the detection of $P$. aeruginosa directly from clinical samples.

The studies comparing sensitivity of culture and speciesspecific PCR for the detection of $P$. aeruginosa from sputa of CF patients indicate comparable efficiency of both methods $[8,16]$, with slightly higher sensitivity for PCR in some studies $[12,18]$ or clearly higher sensitivity for PCR $[13,26]$. We used the PCR format published by De Vos et al. [13] in combination with optimized DNA-extraction methods and used in addition real-time PCR to increase PCR sensitivity further. However, using a sputum dilution series of $P$. aeruginosa, and in accordance to most studies, we found no difference in sensitivity between any of the three culture methods and the most sensitive molecular method, i.e. DNA-extraction with easyMAG protocol Generic 2.0.1 and proteinase K pretreatment combined with any of the three probe-based real-time PCRs. In our hands, culture was more sensitive than PCR and SybrGreen based real-time PCR and the difference was even more pronounced when not optimal DNA-extraction methods were used. It should be noticed that we found no difference between selective and nonselective culture methods, but this may be due to the fact that no bacteria, other than $P$. aeruginosa in the two $P$. aeruginosa positive patients, could be cultured from the sputa of the $8 \mathrm{CF}$ patients. As shown in other studies and confirmed here, the pretreatment of the sample and the DNA-extraction protocol strongly influence the sensitivity of the PCR $[27,28]$. The most sensitive molecular detection method was obtained using the easyMAG Generic 2.0.1 protocol with proteinase $\mathrm{K}$ pretreatment in combination with realtime PCR with the TaqMan probe or the HybProbes. Previous studies showed already that the easyMAG extractor is one of the most sensitive and reliable methods for DNA-extraction [29-31]. An additional advantage of automated DNA-extraction like easyMAG might be the lower sample processing variability [28].

Because both approaches, i.e. culture and (real-time) PCR, have important advantages as well as drawbacks $[14,20,32,33]$, in our opinion, both should be or can be combined. PCR technology has the potential to detect the fastidious P.aeruginosa variants, which are not detected by the routinely used classical culture procedures $[9,10]$, whereas culture yields a complete genome that can be used for e.g. phenotypic susceptibility testing and whole genome based genotyping techniques like RAPD, PFGE and AFLP [22]. Indeed, several of the published studies indicate that there are instances of culture positive PCR negative samples $[11,12,15]$ as well as culture negative PCR positive samples $[11-13,18,19]$, whereby $P$. aeruginosa infection can only be reliably demonstrated when both approaches are combined.

\section{Conclusion}

In summary, we showed, by testing $P$. aeruginosa positive sputum dilution series, that there is no difference in sensitivity for the detection of $P$. aeruginosa in sputum by selective and non-selective culture and by the most efficient DNA-extraction method combined with the most efficient real-time PCR formats, i.e. the probe-based ones. A prospective study, whereby culture is compared with the DNA-extraction/real-time PCR combination that was established in this study as being the most sensitive, has been started and should learn whether both approaches also yield comparable results when used to detect low inocula of $P$. aeruginosa as can be found after recent infection, in the sputum or nasopharyngeal samples of $\mathrm{CF}$ patients not yet colonized by $P$. aeruginosa.

\section{Methods}

\section{Culture and identification of bacteria}

All 8 sputum samples used for this study were collected from cystic fibrosis patients and were cultured on McConkey Agar (MCA) (Becton Dickinson, Cockeysville, MD) and Cetrimide Agar (Cetrimide Broth (Fluka Biochemika, Buchs, Switzerland) $+4 \%$ Bacto Agar (Becton Dickinson))(CA) to check for the presence of Pseudomonas aeruginosa. The two sputum samples from the chronically infected CF patients yielded only $P$. aeruginosa, as identified by tDNA-PCR and confirmed by OprL PCR [13,3437], whereas the six sputum samples from the not chronically infected CF patients were culture and PCR negative for $P$. aeruginosa, as tested in the routine laboratory and confirmed by our laboratory. 


\section{Dilution series of $\mathbf{P}$. aeruginosa positive sputum in $\mathbf{P}$.} aeruginosa negative sputum

All 8 sputa were liquefied by adding v/v Sputasol (Oxoid Ltd, Poole, UK) and incubated during 1 hour at $37^{\circ} \mathrm{C}$. The two liquefied sputa from the CF patients positive for $P$. aeruginosa were pooled and subsequently diluted tenfold (for dilutions nr 1 and 2) and fivefold (for dilutions nr 39) in a pool of liquefied sputa from the six CF patients negative for $P$. aeruginosa. Written informed consent was obtained from the patients for publication of this report. Copies of the written consent are available for review by the Editor-in-Chief of this journal.

\section{Culture techniques}

Fifty $\mu$ l of each dilution was inoculated onto plates (MCA or CA) or into cetrimide broth and incubated for $24 \mathrm{~h}$ at $37^{\circ} \mathrm{C}$ at ambient atmosphere. Cetrimide Broth was subcultured by inoculating $50 \mu \mathrm{l}$ onto a Blood Agar plate (Becton Dickinson), which was incubated for $24 \mathrm{~h}$ at $37^{\circ} \mathrm{C}(\mathrm{CB})$. All dilution cultures were done in triplicate and $P$. aeruginosa colonies were counted.

\section{DNA-extraction protocols}

A total of five different DNA-extraction protocols were carried out on each sputum dilution. Two protocols, i.e. Generic 2.0.1. and Specific B, whereby in the latter a double concentration of silica is used and additional washing steps are included, aiming at DNA-extraction from more difficult samples, using the bioMérieux easyMAG Nuclisense extractor (bioMérieux, Marcy-l'Etoile, France), with and without prior proteinase $\mathrm{K}$ treatment, were compared with each other and with the manual High Pure PCR Template Preparation Kit (Roche Applied Science, Basel, Switzerland), carried out according to the manufacturer's recommendations. Proteinase K pretreatment consisted of incubation of $200 \mu \mathrm{l}$ of each sputum dilution during $1 \mathrm{~h}$ at $55^{\circ} \mathrm{C}$ in $200 \mu \mathrm{l}$ proteinase $\mathrm{K}$ buffer $(1 \mathrm{mg} / \mathrm{ml}$ proteinase
$\mathrm{K}, 0.5 \%$ SDS, $20 \mathrm{mM}$ Tris- $\mathrm{HCl}, \mathrm{pH}$ 8.3) with vortexing every $15 \mathrm{~min}$. For each extraction the start volume was $200 \mu \mathrm{l}$ of liquefied sputum and the elution volume was 50 $\mu \mathrm{l}$. Extracted DNA was stored at $-20^{\circ} \mathrm{C}$ prior to PCR.

The quality of the DNA-extracts obtained with the 5 different extraction protocols was compared by conventional PCR, targeting the oprL gene with $0.5 \mu \mathrm{M}$ of primers PAO1 $\mathrm{S}$ and PAO1 A in combination with agarose gel electrophoresis and ethidium bromide staining and by oprL realtime PCR with $0.5 \mu \mathrm{M}$ of primers PAO $1 \mathrm{~S}$ and PAO $1 \mathrm{~A}$ and $0.1 \mu \mathrm{M}$ of TaqMan probe oprL TM (Table 3).

The DNA-extraction protocol, which enabled the most sensitive detection as assessed by these two PCR formats, was used to compare different PCR and real-time PCR formats.

\section{PCR and real-time PCR formats}

Depending on the type of PCR, detection of $P$. aeruginosa was done using two primer sets (Table 2 and Table 3 ).

Both primer sets are targeting the oprL gene because available sequences of different isolates show that this gene is highly conserved http://www.pseudomonas.com/ related links.jsp\#alleles. A total of six PCR formats (incl. 4 real-time PCR formats) were compared.

Conventional PCR, using the Veriti 96-Well Thermal Cycler (Applied Biosystems, Foster City, Ca.), was done with primers PAO1 S (TET-labeled) and PAO1 A, whereby PCR products were subsequently visualized either with agarose gel electrophoresis and ethidium bromide staining or with fluorescent capillary electrophoresis. Agarose gel electrophoresis was carried out at $100 \mathrm{~V}$ on an agarose gel of $2.5 \%(\mathrm{w} / \mathrm{v})$, containing $1 \mathrm{mg} / \mathrm{ml}$ ethidium bromide and visualized on a UV transilluminator at $540 \mathrm{~nm}$. For

Table 3: Sequences of primers and probes used

\begin{tabular}{|c|c|c|c|}
\hline Primer/Probe & 5'-3' Sequenced & Amplicon size (bp) & Reference or source \\
\hline $\begin{array}{l}\text { PAOI Sa } \\
\text { PAOI Aa }\end{array}$ & $\begin{array}{l}\text { ACC CGA ACG CAG GCT ATG-TET } \\
\text { CAG GTC GGA GCT GTC GTA CTC }\end{array}$ & 92 & TIB Molbiol \\
\hline $\begin{array}{l}\text { oprL Fa } \\
\text { oprL } R^{a}\end{array}$ & $\begin{array}{l}\text { ATG GAA ATG CTG AAA TTC GGC } \\
\text { CTT CTT CAG CTC GAC GCG ACG }\end{array}$ & 504 & {$[13,28]$} \\
\hline oprL-LC-FAMb & TGC GAT CAC CAC CTT CTA CTT CGA GT-FAM & l & TIB Molbiol \\
\hline oprL-LC-ROXb & ROX-CGA CAG CTC CGA CCT GAA G & l & TIB Molbiol \\
\hline oprL TMc & FAM-AGAAGGTGGTGATCGCACGCAGA-BBQ & l & TIB Molbiol \\
\hline
\end{tabular}

a Primers

b HybProbes

c TaqMan Probe.

$\mathrm{d}$ TET, FAM and ROX are fluorescent labels. BBQ: BlackBerry quencher 
capillary electrophoresis, $1 \mu \mathrm{L}$ of PCR product was added to a mixture of $12 \mu \mathrm{L}$ deionised formamide, $0.3 \mu \mathrm{L}$ ROXlabeled GS-400 high-density size standard and $0.2 \mu \mathrm{L}$ ROX labeled GS-500 size standard. This mixture was then electrophoresed on an ABI PRISM 310 (Applied Biosystems), as described previously [35].

Of the four real-time PCR formats, three were carried out on the LightCycler 1.5 Instrument (Roche) using three different LightCycler real-time PCR kits, all with an optimized $\mathrm{MgCl}_{2}$ concentration, i.e. LightCycler FastStart

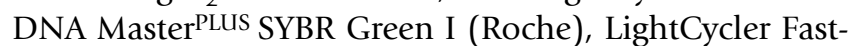
Start DNA Master ${ }^{\text {PLUS }}$ HybProbe (Roche) and LightCycler Taqman Master (Roche) and one was carried out on the ABI7000 instrument, using the commercially available TaqMan Pseudomonas aeruginosa detection kit (Applied Biosystems). For all of these PCR formats, the PCR mixes were prepared as recommended by the manufacturer and also the PCR programs were carried out as prescribed by the manufacturer. For the conventional PCRs, the realtime PCR on the LightCycler 1.5 with SYBR Green I and with the TaqMan probe, the annealing temperature was set to $55^{\circ} \mathrm{C}$, while for the real-time PCR with the HybProbes the annealing temperature was set to $57^{\circ} \mathrm{C}$, as determined by the manufacturer of the primers and probes (TIB Molbiol, Berlin, Germany). For the commercially available TaqMan Pseudomonas aeruginosa detection kit the annealing temperature was set to $60^{\circ} \mathrm{C}$, according to the manufacturers' instructions.

\section{Authors' contributions}

$\mathrm{MV}$ and PD conceived the study. MV, PD, TDB designed the experiments. PD and MV wrote the paper. PD, TDB and LVS performed experiments and analyzed data. JPP, DDV, SVD and FDB helped with the research design and manuscript discussion. SVD and FDB provided patient samples and helped to draft the manuscript. All authors have read and approved the final manuscript.

\section{Acknowledgements}

Pieter Deschaght is indebted to the IWT for PhD research grant IWT-SB/ 7I 184. Thierry De Baere is indebted to the FWO for a postdoctoral research grant. This study was funded by the Belgian Cystic Fibrosis Association.

\section{References}

I. Gibson RL, Burns JL, Ramsey BW: Pathophysiology and management of pulmonary infections in cystic fibrosis. Am J Respir Crit Care Med 2003, 168:918-95I.

2. Saiman L, Siegel J: Infection control in cystic fibrosis. Clin Microbiol Rev 2004, 17:57-71.

3. Kerem E, Corey N, Gold R, Levison H: Pulmonary function and clinical course in patients with cystic fibrosis after pulmonary colonisation with Pseudomonas aeruginosa. J Pediatr 1990, II6:714-7| 9.

4. Henry RL, Mellis CM, Petrovic L: Mucoid Pseudomonas aeruginosa is a marker of poor survival in cystic fibrosis. Pediatr Pulmonol 1992, I 2:158-16I.

5. Kosorok MR, Zeng L, West SE, Rock MJ, Splaingard ML, Laxova A, Green CG, Collins J, Farrell PM: Acceleration of lung disease in children with cystic fibrosis after Pseudomonas aeruginosa acquisition. Pediatr Pulmonol 200I, 32:277-287.

6. Frederiksen B, Koch C, Høiby N: Antibiotic treatment of initial colonization with Pseudomonas aeruginosa postpones chronic infection and prevents deterioration of pulmonary function in cystic fibrosis. Pediatr Pulmonol 1997, 23:330-335.

7. Valerius NH, Koch C, Høiby N: Prevention of chronic Pseudomonas aeruginosa colonisation in cystic fibrosis by early treatment. Lancet 1991, 21:725-726.

8. Van Belkum A, Renders NHM, Smith S, Overbeek SE, Verbrugh HA: Comparison of conventional and molecular methods for the detection of bacterial pathogens in sputum samples from cystic fibrosis. FEMS Immunol Med Microbiol 2000, 27:5 I-57.

9. De Vos D, De Chial M, Cochez C, Jansen S, Tümmler B, Meyer JM, Cornelis P: Study of pyoverdine type and production by Pseudomonas aeruginosa isolated from cystic fibrosis patients: prevalence of type II pyoverdine isolates and accumulation of pyoverdine-negative mutations. Arch Microbiol 200I, 175:384-388.

10. Taylor RFH, Hodson ME, Pitt TL: Adult cystic fibrosis: association of acute pulmonary exacerbations and increasing severity of lung disease with auxotrophic mutants of Pseudomonas aeruginosa. Thorax 1993, 48: 1002-1005.

II. Karpati F, Jonasson J: Polymerase chain reaction for the detection of Pseudomonas aeruginosa, Stenotrophomonas maltophilia and Burkholderia cepacia in sputum of patients with cystic fibrosis. Mol Cell Probes 1996, 10:397-403.

12. da Silva Filho LV, Levi JE, Oda Bento CN, da Silva Ramos SR, Rozov T: PCR identification of Pseudomonas aeruginosa and direct detection in clinical samples from cystic fibrosis patients. J Med Microbiol I 999, 48:357-36I.

13. De Vos D, Lim A, Pirnay JP, Struelens M, Vandenvelde C, Duinslaeger $L$, Vanderkelen A, Cornelis P: Direct detection and identification of Pseudomonas aeruginosa in clinical samples such as skin biopsy specimens and expectorations by multiplex PCR based on two outer membrane lipoprotein genes, oprl and oprL. J Clin Microbiol 1997, 35: I 295- 1299.

14. Pirnay JP, De Vos D, Duinslaeger L, Reper P, Vandenvelde C, Cornelis $P$, Vanderkelen A: Quantitation of Pseudomonas aeruginosa in wound biopsy samples: from bacterial culture to rapid 'realtime' polymerase chain reaction. Crit Care 2000, 4:255-26I.

15. Qin X, Emerson J, Stapp J, Stapp L, Abe P, Burns JL: Use of real-time PCR with multiple targets to identify Pseudomonas aeruginosa and other nonfermenting gram-negative bacilli from patients with cystic fibrosis. IClin Microbiol 2003, 4I:43 I2-43I7.

16. Clarke L, Moore JE, Millar BC, Garske L, Xu J, Heuzenroeder MW, Crowe M, Elborn JS: Development of a diagnostic PCR assay that targets a heat-shock protein gene (groES) for detection of Pseudomonas spp. in cystic fibrosis patients. J Med Microbiol 2003, 52:759-763.

17. Spilker T, Coenye T, Vandamme P, LiPuma JL: PCR-based assay for differentiation of Pseudomonas aeruginosa from other Pseudomonas species recovered from cystic fibrosis patients. J Clin Microbiol 2004, 42:2074-2079.

18. Xu J, Moore J, Murphy PG, Millar BC, Elborn JS: Early detection of Pseudomonas aeruginosa - comparison of conventional versus molecular (PCR) detection directly from adult patients with cystic fibrosis (CF). Annals Clin Microbiol Antimicrob 2004, 3:2 I-26.

19. Motoshima M, Yanagihara K, Yamamoto K, Morinaga Y, Matsuda J, Sugahara K, Hirakata Y, Yamada Y, Kohno S, Kamihira S: Quantitative detection of metallo-beta-lactamase of blalMP-clusterproducing Pseudomonas aeruginosa by real-time polymerase chain reaction with melting curve analysis for rapid diagnosis and treatment of nosocomial infection. Diagn Microbiol Infect Dis 2008, 61:222-226.

20. Döring G, Unertl K, Heininger A: Validation criteria for nucleic acid amplification techniques for bacterial infections. Clin Chem Lab Med 2008, 46:909-918.

21. West SEH, Zeng L, Lee BL, Kosorok M, Laxova A, Rock MJ, Splaingard MJ, Farrell PM: Respiratory infection with Pseudomonas aeruginosa in children with cystic fibrosis: early detection by serology and assessment of risk factors. JAMA 2000, 287:2958-2967.

22. O'Callaghan EM, Tanner MS, Boulnois GL: Development of a PCR probe test for identifying Pseudomonas aeruginosa and Pseudomonas (Burkholderia) cepacia. J Clin Pathol I 994, 47:222-226. 
23. Lavenir R, Jocktane D, Laurent F, Nazaret S, Cournoyer B: Improved reliability of Pseudomonas aeruginosa PCR detection by the use of the species-specific ecf $X$ gene target. J Microb Methods 2007, 70:20-29.

24. Jaffe RI, Lane DL, Bates CW: Real-time identification of Pseudomonas aeruginosa direct from clinical samples using a rapid extraction method and polymerase chain reaction (PCR). J Clin Lab Anal 2001, 15:131-137.

25. Anuj SN, Whiley DM, Kidd TJ, Bell SC, Wainwright CE, Nissen MD, Sloots TP: Identification of Pseudomonas aeruginosa by a duplex real-time polymerase chain reaction assay targeting the ecf $X$ and the gyrB genes. Diagn Microb Infect Dis 2009, 63: $|27-| 3 \mid$.

26. da Silva Filho LV, Tateno AF, Martins KM, Chernishev ACA, De Oliveira Garcia D, Haug M, Meisner C, Rodrigues JC, Döring G: The combination of PCR and serology increases the diagnosis of Pseudomonas aeruginosa colonization/infection in cystic fibrosis. Ped Pulmonol 2007, 42:938-944.

27. Dauphin LA, Moser BD, Bowen MD: Evaluation of five commercial nucleic acid extraction kits for their ability to inactivate Bacillus anthracis spores and comparison of DNA yields from spores and spiked environmental samples. J Microb Methods 2009, 76:30-37.

28. Dundas N, Leos NK, Mitui M, Revell P, Rogers BB: Comparison of automated nucleic acid extraction methods with manual extraction. J Mol Diagn 2008, I0:31|-316.

29. Loens K, Bergs K, Ursi D, Goossens H, leven M: Evaluation of NucliSens easyMAG for automated nucleic acid extraction from various clinical specimens. J Clin Microbiol 2007, 45:42I-425.

30. Chan KH, Yam WC, Pang CM, Chan KM, Lam SY, Lo KF, Poon LL, Peiris JS: Comparison of the NucliSens easyMAG and Qiagen BioRobot 9604 nucleic acid extraction systems for detection of RNA and DNA respiratory viruses in nasopharyngeal aspirate samples. J Clin Microbiol 2008, 46:2195-2199.

31. Wilson D, Yen-Lieberman B, Reischl U, Warshawsky I, Procop GW: Comparison of five methods for extraction of Legionella pneumophila from respiratory specimens. J Clin Microbiol 2004, 42:5913-5916.

32. Vaneechoutte $M$, Van Eldere J: The possibilities and limitations of nucleic acid amplification technology in diagnostic microbiology. J Med Microbiol 1997, 46: I 88-194.

33. Barken KB, Haagensen JAJ, Tolker-Nielsen T: Advances in nucleic acid-based diagnostics of bacterial infections. Clin Chim Acta 2007, 384: I- II.

34. Baele M, Baele P, Vaneechoutte M, Storms V, Butaye P, Devriese LA, Verschraegen G, Gillis M, Haesebrouck F: Application of tRNA intergenic spacer PCR for identification of Enterococcus species. J Clin Microbiol 2000, 38:4201-4207.

35. Van daele $S$, Franckx H, Verhelst R, Schelstraete P, Haerynck F, Van Simaey L, Claeys G, Vaneechoutte M, De Baets F: Epidemiology of Pseudomonas aeruginosa in a cystic fibrosis rehabilitation centre. Eur Respir J 2005, 25:474-48I.

36. Van daele S, Vaneechoutte M, De Boeck K, Knoop C, Malfroot A, Lebecque P, Leclercq-Foucart J, Van Schil L, Desager K, De Baets F: Survey of Pseudomonas aeruginosa genotypes in colonised cystic fibrosis patients. Eur Respir J 2006, 28:740-747.

37. Schelstraete $P$, Van daele S, De Boeck K, Proesmans M, Lebecque $P$, Leclercq-Foucart J, Malfroot A, Vaneechoutte M, De Baets F: Pseudomonas aeruginosa in the home environment of newly infected cystic fibrosis patients. Eur Respir J 2008, 3 I:822-829.

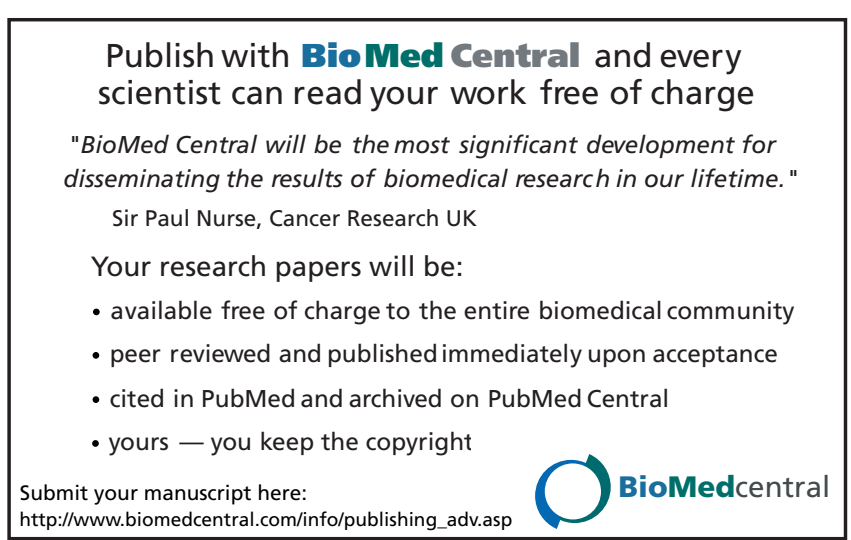

